\title{
La imbricación vida-poder en el pensamiento de Michel Foucault y Giorgio Agamben ${ }^{1}$
}

\section{The overlapping life-power in the thought of Michel Foucault and Giorgio Agamben}

\author{
Marcelo Raffin ${ }^{2}$ \\ Consejo Nacional de Investigaciones Científicas y Técnicas CONICET \\ Universidad de Buenos Aires, Argentina
}

Recepción: 19 de febrero del 2018

Evaluación: 28 de febrero del 2018

Aceptación: 10 de mayo del 2018

\footnotetext{
1 Este artículo constituye una difusión de resultados parciales de las investigaciones La tensión metafisica-política en la "ontología" de Michel Foucault y de Giorgio Agamben y La noción de política en Michel Foucault, Giorgio Agamben y Hannah Arendt a partir de las categorías de sujeto y acción desarrolladas en el Consejo Nacional de Investigaciones Científicas y Técnicas (CONICET) de Argentina durante los últimos cinco años, y del Proyecto de Investigación UBACyT 20020150100181BA Mod. I La relación verdad-subjetividad en la filosofía de Michel Foucault en los años 1970 y 1980, Programación Científica 2016-2018, Instituto de Investigaciones Gino Germani (IIGG), Facultad de Ciencias Sociales de la Universidad de Buenos Aires (UBA) (Resolución CS 4756/16), de la Secretaría de Ciencia y Técnica (SECyT) de la UBA, del que soy director.

2 Habilitación (HDR - Habilitation à diriger des recherches -) y Doctor en Filosofía por la Universidad de París 8. Actualmente, me desempeño como investigador del CONICET en el IIGG y como profesor titular regular de Filosofía, en la Facultad de Ciencias Sociales de la UBA. Mis últimas investigaciones se centran en los problemas de la subjetividad y la política en el mundo contemporáneo, en particular, siguiendo los desarrollos propuestos por Foucault, Agamben y Arendt. Me especializo, asimismo, en cuestiones de derechos humanos. Publiqué recientemente Droits de l'homme, sujet et devenir. L'expérience contemporaine du Cône sud d'Amérique latine (L'Harmattan, 2017) y, como editor, La noción de política en el pensamiento de Agamben, Esposito y Negri (Aurelia Rivera, 2015).

Correo electrónico: raffinmarcelo@yahoo.com.
} 


\section{Resumen}

Este artículo pretende analizar la particular relación de imbricación que Michel Foucault y Giorgio Agamben han venido a establecer entre la vida humana y el poder. A tal fin, se propone un recorrido por los dos momentos centrales de su producción que permiten dar cuenta de dicha imbricación: en el caso de Agamben, el referido a la investigación "homo sacer" y, en el de Foucault, el de su investigación en torno de la biopolítica como acontecimiento decisivo de la modernidad. Ambas investigaciones han redundado, entre otros aspectos, pero de manera central, en la configuración de la vida humana en su relación con el poder. En cada uno de los momentos elegidos en las producciones de los filósofos, se analizan las nociones centrales que componen cada investigación: nuda vida, "homo sacer", estado de excepción y "oikonomía", en el primer caso; y biopolítica y gubernamentalidad, en el segundo. Finalmente, se contrastan ambas formulaciones filosóficas a fin de sopesar los alcances y las potencialidades que implican frente al análisis que proponen. Este breve ejercicio de análisis sobre la relación entre la vida y el poder en los dos filósofos, pretende poner en evidencia los riesgos a los que nos exponen ciertos presupuestos frecuentes que fundamentan y dan sentido a las ideas y a las prácticas políticas contemporáneas.

Palabras clave: Vida, poder, Foucault, Agamben.

\section{Abstract}

This article attempts to analyze the particular relationship of the overlapping that Michel Foucault and Giorgio Agamben have established between human life and power. Such that, it is proposed a travel across the two key moments of its production that allow to consider this overlapping: in the case of Agamben, the moment referring to the research "Homo sacer" and, for Foucault, that of his research concerning bio-politics as a decisive event of modernity. Both researches have reappeared, among other aspects, but mainly, in the configuration of human life and its relationship with power. At each of these chosen moments of the philosophers productions, it is analyzed the main notions that compose each research: bare life, "homo sacer", state of exception and "oikonomics", in the first moment, and biopolitics and governmentality, in the second one. Finally, both philosophical formulations are compared such that their reaching and potentialities can be weighted, for they contrast against the analysis they propose. This short analysis on 
the relationship between life and power in the two philosophers attempts to show the risks to which certain assumptions expose us. Such frequent assumptions support and yield a north to the contemporaneous ideas and political practices.

Keywors: Life, power, Foucault, Agamben.

\section{L'imbrication vie-pouvoir dans la pensée de Michel Foucault et Giorgio Agamben}

\section{Résumé}

Cet article tente d'analyser la relation d'imbrication particulière que Michel Foucault et Giorgio Agamben ont établi entre la vie humaine et le pouvoir. Pour ce faire, un parcours des deux moments centraux de leur production, qui permette de rendre compte de ladite imbrication, est proposé : dans le cas d'Agamben, celui qui se réfère à la recherche « homo sacer» et, dans le cas de Foucault, celui de son travail de recherche autour de la biopolitique comme un évènement décisif de la modernité. Les deux travaux de recherche ont concerné, entre autres aspects, mais de façon centrale, la configuration de la vie humaine dans sa relation avec le pouvoir. Dans chacun des moments des productions des philosophes qui ont été choisies, on analyse les notions centrales qui constituent chaque travail de recherche : vie nue, « homo sacer ", état d'exception et " oikonomia », dans le premier cas ; et biopolitique et gouvernabilité dans le second. Pour finir, les deux formulations philosophiques sont contrastées, dans le but de soupeser les portées et les potentialités qu'elles impliquent vis-à-vis de l'analyse qu'elles proposent. Ce bref exercice d'analyse de la relation entre la vie et le pouvoir chez les deux philosophes, cherche à mettre en évidence les risques auxquels nous exposent certains postulats courants qui sont le fondement et qui donnent du sens aux idées et aux pratiques politiques contemporaines.

Mots-clés : La vie, le pouvoir, Foucault, Agamben. 


\section{A imbricação vida-poder no pensamento de Michel Foucault e Giorgio Agamben}

\section{Resumo}

Este artigo pretende analisar a particular relação de imbricação que Michel Foucault e Giorgio Agamben estabelecem entre a vida humana e o poder. Para tal fim, propõe-se um percurso pelos dois momentos centrais de sua produção, os quais permitem dar conta dessa imbricação: no caso de Agamben, o referido na investigação "homo sacer" e, no de Foucault, em sua investigação em torno da biopolítica como acontecimento decisivo da modernidade. Ambas investigações têm redundado entre outros aspectos, mas, de maneira central, na configuração da vida humana em sua relação com o poder. Em cada um dos momentos escolhidos nas produções dos filósofos, analisam-se as noções centrais que compõem cada investigação: vida nua, "homo sacer", estado de exceção e "oikonomía", no primeiro caso, e biopolítica e governamentalidade, no segundo. Finalmente, contrastam-se ambas formulações filosóficas a fim de ponderar os alcances e as potencialidades que implicam na análise que propõem. Esse breve exercício de análise sobre a relação entre a vida e o poder nos dois filósofos tenta colocar em evidência os riscos aos quais nos expõem certos pressupostos frequentes que fundamentam e dão sentido às ideias e às práticas políticas contemporâneas.

Palavras-chave: Vida, poder, Foucault, Agamben. 


\section{Introducción}

Este artículo pretende analizar la particular relación de imbricación que Michel Foucault y Giorgio Agamben han venido a establecer entre la vida humana y el poder. En efecto, desde sus perspectivas de análisis, y, en el caso de Foucault particularmente a partir de la modernidad, se puede constatar, en las sociedades occidentales y en aquellas que quedan bajo su influencia y dominio, una imbricación de la vida humana y el poder en la relación de las dimensiones política y ontológica. Estas ideas se vinculan, en parte, con algunos ejes de análisis centrales de las investigaciones actuales relativas a las relaciones de poder en el mundo contemporáneo y muy especialmente de la arena política, y a las configuraciones o "modalizaciones" de las formas de la subjetividad, en lo que se ha dado en denominar, en particular, el campo de estudios de la "biopolítica".

A continuación, analizaré algunas categorías y nociones fundamentales en ambos filósofos, que son claves para comprender la relación indicada. A tal fin, propondré un recorrido por dos momentos centrales de su producción, que permiten trazar una cartografía de la formulación de este problema en cada uno de ellos. Ambos momentos refieren a una propuesta fuerte de ideas que permiten dar cuenta de la relación de imbricación entre la vida y el poder. En Agamben, ese momento refiere sobre todo a la investigación que ha desarrollado bajo la invocación de la figura del "homo sacer", con el fin de dar cuenta de la configuración de la vida humana en su relación con el poder, mientras que en el de Foucault, a su investigación en torno de la biopolítica propiamente, como acontecimiento decisivo de la modernidad, que ha redundado, entre otras cosas, en una cierta forma específica del viviente humano que produce, asimismo, una cierta configuración en detrimento de otras. Finalmente, se tratará de contrastar ambas formulaciones filosóficas a fin de sopesar los alcances y las potencialidades que implican frente al diagnóstico que proponen.

\section{Giorgio Agamben: la investigación "homo sacer"}

Los desarrollos de la investigación "homo sacer" refieren, grosso modo, a la investigación sobre la política, el derecho y la economía que Agamben ha llevado adelante durante los últimos veinticinco años. La saga comprende las siguientes obras: Homo sacer. El poder soberano y la nuda vida (1995), Lo que queda de Auschwitz. El archivo y el testigo. Homo sacer III (1998), Estado de excepción. Homo sacer II, I (2003), El Reino y la Gloria. Para una genealogía teológica 
de la economía y del gobierno. Homo sacer II, 2 (2007), El sacramento del lenguaje. Arqueología del juramento. Homo sacer II, 3 (2008), Altísima pobreza. Reglas monásticas y forma de vida. Homo sacer, IV, I (2011), Opus Dei. Arqueología del oficio. Homo sacer, II, 5 (2012), El uso de los cuerpos. Homo sacer IV, 2 (2014) y Stasis. La guerra civil como paradigma político. Homo sacer II, 2 (2015), a las que podemos agregar, entre otras, La comunidad que viene (1990/2001), Medios sin fin. Notas sobre la politica (1996) y Lo abierto. El hombre y el animal (2002) y un conjunto de artículos incluidos en La potencia del pensamiento (2005), Profanaciones (2005) y Desnudeces (2009).

Agamben persigue varios objetivos con esta investigación, entre los cuales, en mi opinión, se deben mencionar tres fundamentales. En primer lugar, el propósito central de este conjunto es, como el propio Agamben lo explicita, llevar adelante una genealogía del poder en Occidente (2007, p. 9) en el sentido general de una genealogía de lo que Foucault denominó "gubernamentalidad", entendida como punto de fuga entre una teoría jurídico-institucional del poder y el modelo biopolítico constituido por ciertas tecnologías y dispositivos individualizantes y totalizantes. En segundo lugar, la investigación "homo sacer" se presenta, asimismo, como una respuesta a la sangrienta mistificación del nuevo orden planetario que se configura una vez terminada la Guerra Fría en la década de 1990 (Agamben, 2005, p. 16).

Pero esta investigación también constituye sobre todo (tercer objetivo y probablemente el más importante), una verdadera "saga" sobre la ontología occidental. En efecto, Agamben sostiene en Homo sacer I, que uno de los resultados a los que arribó su investigación es que "la implicación de la nuda vida en la esfera política constituye el núcleo originario -aunque oculto- del poder soberano" $(2005, \text { p. 9) })^{3}$. Es más, el filósofo explicita que "se puede decir de hecho que la producción de un cuerpo biopolítico es el acto originario del poder soberano" (2005, p. 9. Itálica en el original).

Agamben concluye entonces que "la política se presenta como la estructura propiamente fundamental de la metafísica occidental, en tanto ocupa el umbral en el que se cumple la articulación entre el viviente y el logos" (2005, p. 11). Esta operación fundamental del poder sobre la vida es denominada por Agamben como "politización" de la "nuda vida" o captura y configuración de la vida natural por parte del poder.

Toda vez que no se indique lo contrario, la traducción es propia. 
Agamben sostiene que esta articulación entre la vida y el poder se inscribe en la investigación foucaultiana sobre la biopolítica, aunque, a diferencia del filósofo francés, afirma que la biopolítica es al menos tan antigua como la excepción soberana. En este sentido, al ubicar la vida biológica (nuda vida) en el centro de sus cálculos, el Estado moderno no hace más que poner en evidencia el vínculo secreto entre el poder y la nuda vida, restableciendo así, en sus propias palabras, "según una correspondencia tenaz entre lo moderno y lo arcaico que puede ser observada en los ámbitos más diversos", "el más inmemorial de los arcana imperii [secretos o misterios del poder]" (Agamben, 2005, p. 9).

¿Qué significa esta relación entre formas políticas y formas de lo "humano"? ¿Cuál es ese vínculo que Agamben caracteriza como secreto, que une el poder a la nuda vida y restablece así una continuidad y una correspondencia firmes entre lo moderno y lo arcaico? ¿Cuál es el misterio de los misterios del poder? Y, en definitiva, ¿qué es aquello que Agamben pretende demostrar con su investigación "homo sacer"? Trataré de responder a estas preguntas en el resto de este apartado, a partir de los desarrollos conceptuales que se desprenden de la investigación "homo sacer".

Agamben comienza su trabajo retomando el concepto de biopolítica elaborado por Foucault en La voluntad de saber, tomo I de Historia de la sexualidad (1976), como el acontecimiento decisivo de la modernidad que "hace entrar la vida y sus mecanismos en el ámbito de los cálculos explícitos y hace del poder-saber un agente de transformación de la vida humana" (Foucault, 1995, p. 188), con el fin de resignificar el lugar de la vida como un campo de libre disposición que hace posible la "nuda vida" o vida desnuda, biológica, desprovista de todo valor y atributo, pero que, en su visión, hace remontar a los orígenes del proceso civilizatorio occidental.

En su posición, es esa nuda vida lo único que subsiste cuando, según las exigencias de la polis contemporánea, se hace necesario el estado de excepción como un estado, sin embargo, cada vez más permanente. La figura en la que confluyen la nuda vida y el estado de excepción es la del "homo sacer" cuya vida (como lo define esta figura del derecho romano arcaico, que constituye la primera sanción de su sistema penal) puede ser dispuesta sin ningún reparo, desprovista de cualquier atributo que la haría intocable, y, por lo tanto, muerta, sin que ello acarree reproche legal alguno. 
En estas elaboraciones, las contribuciones de Hannah Arendt sobre la condición humana de la "labor" -que la pensadora afirma en La condición humana (1958), como aquella referida a las actividades del hombre que solo atienden a sus necesidades biológicas, así como el ejercicio del juicio irreflexivo que quita toda profundidad y carácter extremo al mal realizado produciendo su banalización (y que desarrolla en Eichmann en Jerusalén. Un informe sobre la banalidad del mal, 1963, y en escritos posteriores)- vienen a complementar el cuadro del funcionamiento de la biopolítica moderna para Agamben.

Entre los ascendentes teóricos de estos desarrollos agambenianos, se podría decir que Foucault y Arendt se ubican al principio y al final de las categorías señaladas. Lo que sorprende a Agamben es que a pesar de que ambos pensadores descubrieron el papel fundamental de la vida en la política moderna, paradójicamente, nunca fueron más allá de un cierto punto que habría podido explicar, de manera explícita, la matriz fundacional de nuestro mundo. Es Agamben mismo quien se propone entonces llevar adelante esta tarea. Pero entre los ascendentes filosóficos aparecen, asimismo, Walter Benjamin (1980, tesis VIII) y Carl Schmitt (2005), en particular con la noción de estado de excepción (Ausnahmezustand) y, principalmente, dos fantasmas que sobrevuelan y marcan el tono de toda la investigación: Martin Heidegger, de manera determinante, $y$, en menor medida y sobre todo vía la interpretación heideggeriana de su filosofía, Friedrich Nietzsche.

Revisemos las nociones centrales de la primera parte de la "saga" investigativa homo sacer, que Agamben desarrolla en las primeras obras que componen los resultados de este trabajo, en particular, Homo sacer I, Lo que queda de Auschwitz, Estado de excepción y El Reino y la Gloria, que publica entre 1995 y 2007.

En Homo sacer I, Agamben propone tres nociones centrales a las que arriba en la investigación y que se transforman, en lo sucesivo, en categorías fundamentales de su producción teórica: la nuda vida (nuda vita), "homo sacer" y el estado de excepción, íntimamente ligadas.

El filósofo explica que la distinción practicada en la Antigüedad por los griegos, entre los términos zoé y bíos para referir a la vida, es decir, tal como él los define respectivamente, entre el simple hecho de vivir que los hombres comparten con todos los seres vivientes (animales, hombres o dioses), y la forma o la manera de vivir propia de un individuo o un grupo, la vida calificada por la polis, la vida cultural, desapareció en la modernidad o, mejor dicho, la zoé fue incluida en la polis provocando la expulsión del bios. 
Esta inclusión se produjo a través de una exclusión o bien, para decirlo con Agamben, mediante una "exclusión inclusiva", una ex-ceptio o excepción. He aquí la nuda vida, la vida desprovista de todo atributo, el simple hecho de vivir, que constituye, según Agamben, el eje de la matriz sociopolítica moderna, el núcleo originario -aunque oculto- del poder soberano y no ya el bíos, tal como lo enuncian o declaran los principales textos político-jurídicos de esta era. En consecuencia, en la visión agambeniana, "la nuda vida tiene, en la política occidental, ese privilegio singular de ser aquello cuya exclusión funda la polis" (2005, p. 10).

La nuda vida corresponde a una forma "humana" particular que Agamben caracteriza como "homo sacer". Se trata de la vida que puede ser muerta y que es, al mismo tiempo, insacrificable. En efecto, Agamben señala que "homo sacer" remite a una figura del derecho romano arcaico en la que la vida humana es incluida en el orden jurídico únicamente a través de su posibilidad de ser muerta sin sanción, en la medida en que se trata de la primera pena que impone el derecho penal romano arcaico en virtud de haberse infringido el orden sacro (aquel instituido por los dioses). En este caso, no queda otra alternativa que entregar esa vida a los dioses, quienes deberán decidir qué hacer con la infracción cometida. Pero ello acarrea la muerte de quien ha sido inculpado por la infracción, a fin de que pueda entrar en el orden sacro, sin que dicha muerte constituya ni un sacrificio ni un homicidio. De ahí la situación paradojal implicada por la figura del "homo sacer" respecto del tratamiento de la vida (es decir, de su muerte).

En este punto, Agamben formula una de sus tesis fundamentales respecto de la relectura que hace de la biopolítica foucaultiana en términos de la configuración de la vida por parte del poder, al señalar que la tesis del filósofo francés debe ser corregida o al menos completada, en el sentido de que aquello que caracteriza la política moderna no es la inclusión de la zoé en la polis, que él considera en sí muy antigua, ni simplemente el hecho de que la vida como tal se vuelve un objeto eminente de los cálculos y las previsiones del poder estatal. En su opinión, el hecho decisivo es más bien que "el espacio de la nuda vida, situado en el origen al margen de la organización política, termina progresivamente por coincidir con el espacio político, en el que exclusión e inclusión, exterior e interior, bíos y zoé, derecho y hecho, entran en una zona de indiferenciación irreductible" (Agamben, 2005, p. 12). 
Es aquí donde entra en escena la tercera noción: el estado de excepción en el que la nuda vida es, al mismo tiempo, excluida y capturada por el orden jurídico-político, constituyendo, para Agamben, el fundamento oculto sobre el que reposa todo el sistema político. Cuando sus fronteras se esfuman, la nuda vida que "habitaba en él se libera en la polis y deviene al mismo tiempo el sujeto y el objeto del orden político y de sus conflictos, el lugar único tanto de la organización del poder estatal como de la emancipación respecto de él” (2005, p. 12).

En consecuencia, concluye Agamben, la aporía de la democracia moderna consiste en poner en juego la libertad y la felicidad de los hombres en el lugar mismo de la nuda vida, que marcaba su servidumbre. En efecto, el filósofo afirma que, detrás del largo proceso conflictivo que lleva al reconocimiento de los derechos y las libertades formales, se encuentra el cuerpo del "homo sacer" con su doble soberano, su vida insacrificable y, sin embargo, paradójicamente, "matable" (uccidibile). Pero, a renglón seguido, Agamben se ocupa de aclarar que tomar conciencia de esta aporía no significa subestimar las conquistas y los esfuerzos de la democracia, sino intentar comprender por qué, en el mismo momento en el que parecía haber triunfado definitivamente sobre sus adversarios y haber alcanzado su apogeo, se mostró incapaz de salvar de una destrucción sin precedentes a esa vida a cuya liberación y felicidad había dedicado todos sus esfuerzos.

En un pasaje harto provocador de la "Introducción" a Homo sacer I, Agamben explicita esta aporía de la democracia moderna, que marca su destino desde su aparición y que, según afirma, por ello mismo, la vincula, mediante una complicidad secreta, con el totalitarismo, es decir, su enemigo más encarnizado. De ahí que concluya que la política "no conoce hoy ningún otro valor (ni, en consecuencia, ningún otro disvalor) que la vida, y en la medida en que las contradicciones que ello implica no sean resueltas, el nazismo y el fascismo, que habían hecho de la decisión sobre la nuda vida el criterio político supremo, permanecerán dramáticamente actuales" (Agamben, 2005, p. 13-14).

Esta es la razón por la que Agamben identifica el campo de concentración y de exterminio como nomos de la modernidad y su matriz como la metáfora que define y acecha el orden sociopolítico contemporáneo.

Pero el filósofo completa su cuadro de resultados de la investigación "homo sacer" con un cuarto elemento: el paradigma de una teología económica, entendido como el sustrato de lo que denomina la "máquina gubernamental". En El Reino y la Gloria, Agamben sostiene que el poder, primero en 
Occidente y luego a través de la empresa imperialista europea en el resto del mundo, ha asumido, a la par del paradigma de la soberanía, la forma de una oikonomía o lo que, en su interpretación, Foucault denomina "gobierno de los hombres". Basándose en la noción cristiana de una oikonomía trinitaria, tal como es entendida en los primeros siglos de la teología cristiana, Agamben propone esta hermenéutica de la oikonomía como gestión y gobierno divinos del mundo, es decir, de la casa celestial en la Tierra, como un paradigma de administración, gestión y gobierno de la vida humana.

Así, en su visión, el dispositivo de la oikonomía trinitaria constituye un laboratorio privilegiado para observar el funcionamiento y la articulación (al mismo tiempo, interna y externa) de la "máquina gubernamental". La gloria viene a jugar un papel central respecto del poder, puesto que la relación entre gloria y oikonomía constituye la estructura última de la máquina gubernamental en Occidente, de suerte que ella misma se presenta como el arcano central del poder, como el nexo indisoluble que lo liga al gobierno y a la oikonomía. La gloria es necesaria porque el trono, como centro de la máquina gubernamental, está vacío, es decir, carece de fundamento por lo que es necesario proceder a proveer alguno posible.

Estos desarrollos filosóficos, a los que arriba Agamben en su investigación "homo sacer", permiten, en su opinión, comprender el umbral de nuestro mundo por el que se han vuelto posibles prácticas aparentemente tan contradictorias con los ideales de la política moderna como las concentracionarias, las genocidas, las totalitarias, las imperialistas, las terroristas, pero también las que posibilitan la creciente exclusión de los regímenes democráticos. El análisis propuesto por Agamben habilita un abordaje de estas formas político-culturales que recusa el carácter extraordinario que, desde distintos saberes, se les asigna. Esta tarea de desvelamiento, que su investigación hace posible, permite tornar conscientes los riesgos a los que nos exponen ciertas creencias y prácticas corrientes de la praxis política contemporánea.

\section{Michel Foucault: la investigación sobre la biopolítica}

Una de mis hipótesis de lectura sobre la "obra"4 o producción de Foucault es que siempre estuvo obsesionado por saber cómo se formó la subjetividad

4 Empleo el término "obra" siendo consciente de la crítica que Foucault formula a esta noción. De
todas formas, y como lo señala Didier Éribon (1989) en la biografía que le dedica, como académico,

Raffin, M. (2018). La imbricación vida-poder en el pensamiento de Michel Foucault y

Giorgio Agamben. Cuestiones de Filosofía, 4 (22), 117-137. 
moderna. La respuesta que ofrece a esta pregunta se encuentra, en mi opinión, en la forma en que se acerca a la historia y la deconstruye. Foucault descree de las historias del pasado que pretenden dar cuenta de él a través del encadenamiento causal de los hechos. Está convencido de que este proceder esconde verdad con su mentira, y es esa verdad a la que apunta, la que persigue, la que desea des-encubrir en la trama de relaciones socio-históricas. Ello constituye la materia específica de la arqueología y la genealogía como métodos privilegiados de acceso al pasado.

Una de las respuestas fuertes a la pregunta sobre la formación de la subjetividad moderna, aparece en Foucault, en uno de sus momentos decisivos, en una ecuación o correlación fundamental entre prácticas sociales de encierro que tienen lugar durante los siglos XVII y XVIII en Europa occidental, entendidas como prácticas de poder-saber, que llevaron a la producción de determinados dominios de saber, que, a su vez, generaron nuevos objetos y nuevos sujetos, entre los cuales aparece, como una resultante y en forma paradigmática, el sujeto moderno. Pero también, y al tiempo que tienen lugar estas prácticas sociales de encierro, se producen determinadas técnicas y dispositivos que se aplican a las poblaciones (al "cuerpo-especie"), aquello que Foucault denomina justamente biopolítica.

Es así como la cuestión de la biopolítica aparece en Foucault dentro de sus desarrollos sobre el poder -recordemos que el propio Foucault (1994) rechazó la idea de haber pretendido elaborar una "teoría del poder", sino que, más bien, en sus investigaciones sobre el sujeto moderno, se topó con él- como uno de los dos polos centrales que el Foucault de La voluntad de poder denomina "biopoder" o "poder sobre la vida": las disciplinas (una anátomo-política del cuerpo humano, cuyo eje es el "cuerpo-máquina") y los controles reguladores (una biopolítica de las poblaciones, cuyo eje es el "cuerpo-especie").

Tomando en consideración la definición del hombre dada por Aristóteles en Política, al final de La voluntad de saber, Foucault resume el proceso a través del cual, al comienzo de la modernidad, la vida natural empieza a ser integrada en los mecanismos y los cálculos del poder del Estado y la política

Foucault entró en una trama de relaciones que lo hizo transformarse en el "autor" de una "obra" respecto de la que se desarrolló un aparato de "comentarios" que pretendieron y pretenden aún restituir su producción a esas figuras de las que siempre buscó desprenderse. Es entonces en este sentido que utilizo el término. 
deviene "bio-política": "Durante milenios, el hombre siguió siendo lo que era para Aristóteles: un animal viviente y además capaz de una existencia política; el hombre moderno es un animal en cuya política está en cuestión su vida de ser viviente" (Foucault, 1976, p. 188).

Según Foucault, el "umbral de modernidad biológica" de una sociedad se sitúa allí donde la especie y el individuo, como un simple cuerpo viviente, se vuelven el desafío de las estrategias políticas. Tal como señala Agamben en Homo sacer I, desde 1978, en sus cursos del Collège de France, Foucault comienza a definir el pasaje del "Estado territorial" al "Estado de población" y la importancia creciente de la vida biológica y de la salud de la nación, como un problema específico del poder político que se transforma progresivamente en "gobierno de los hombres" y "gubernamentalidad" ("gouvernementalité") (Foucault, 2004, lección del $1^{\text {o }}$ de febrero de 1978). Foucault señala que de este nuevo tipo de gobierno se desprende una suerte de "animalización" del hombre producida por las técnicas políticas más sofisticadas. Es el momento, en consecuencia, de la aparición en la historia, no solo de la multiplicación de las posibilidades de las ciencias humanas, sino también de la posibilidad simultánea de la protección de la vida y de la autorización de su supresión.

Foucault afirma entonces explícitamente que habría que hablar de "biopolítica" para designar, tal como señalé previamente, "aquello que hace entrar la vida y sus mecanismos en el ámbito de los cálculos explícitos y hace del poder-saber un agente de transformación de la vida humana" (1995, p. 188). Desde esta perspectiva, el desarrollo y el triunfo del capitalismo no habrían sido posibles sin la difusión de la disciplina y los controles reguladores realizada por el nuevo "biopoder" o "poder sobre la vida" que creó, a través de una serie de tecnologías apropiadas, los cuerpos dóciles que necesitaba, tanto a nivel individual como colectivo (poblaciones).

Pero la noción de biopolítica se encuentra ya en ciernes en Vigilar y castigar. Nacimiento de la prisión (1975) y comienza a desarrollarse al tiempo que en La voluntad de saber, en Defender la sociedad, el curso del Collège de France de 1976. La noción de biopolítica será igualmente desarrollada por Foucault en sus cursos de 1977-1978 (Seguridad, territorio, población), de 1978-1979 (Nacimiento de la biopolítica) y, adicionalmente, en una serie de artículos de la misma época y posteriores, entre los cuales cabe mencionar, particularmente, “'Omnes et singulatim': hacia una crítica de la razón política", que presenta mediante dos conferencias en la Universidad 
de Stanford, en California, en octubre de 1979, y que será publicado en forma unitaria en 1981.

La noción de "gobierno" desembocará más específicamente, entre otras, en la de "poder pastoral" o poder individualizador del poder centralizado de los Estados modernos, y, finalmente, en la "razón de Estado", como corazón de la racionalidad política, como poder totalizante sobre lo general (las poblaciones) y sobre lo particular (el cuerpo individual), es decir, sobre "omnes et singulatim". Estas operaciones que terminaron en la "gubernamentalización" del Estado en la modernidad, se produjeron por medio del pastorado, la nueva técnica diplomático-militar y, finalmente, la policía. El poder es entendido, de aquí en adelante por Foucault, como gobierno en la doble dimensión individual y colectiva y se desplegará mediante lo que el filósofo propone denominar "gubernamentalidad".

Foucault centra su análisis de la biopolítica particularmente en el dispositivo de sexualidad, en la medida en que este dispositivo le permite ilustrar claramente cómo se despliega la biopolítica en su doble dimensión individual y colectiva. El dispositivo de sexualidad, como dispositivo de poder-saber, construirá sujetos normales y anormales o desviados de la norma. Es justamente a partir de la sexualidad que un cierto poder podrá desarrollar su máximo dominio, puesto que ya no se trata solo de un poder exterior y coactivo, sino de un poder interior, del poder que el propio sujeto ejerce sobre sí mismo a través de un régimen de gobierno de sí.

Pero el panorama abierto por el análisis foucaultiano de la biopolítica implica, a su vez, la profundización de los aspectos referidos a la resistencia al poder, que coexisten, a la par, con los que hacen a la represión y la dominación. Ya desde La voluntad de saber, Foucault afirma que allí donde hay poder, hay resistencia y que, por ello mismo, ésta nunca se encuentra en posición de exterioridad respecto de él (Foucault, 1995, p. 125-126). Foucault vuelve sobre esta idea en el curso de 1978 con la noción de "contraconductas", al sostener que hay una correlación inmediata y fundacional entre conducta ligada a una determinación de poder- y contraconducta -como resistencia a ese poder y ejercicio de un poder en otro sentido-(Foucault, 2004, p. 199) y la profundiza en "Omnes et singulatim", donde se ocupa de aclarar que no existe poder sin rechazo o revuelta en potencia y que resistir o rebelarse contra una forma de poder exige el cuestionamiento de la forma de racionalidad presente (Foucault, 1994, p. 161). 
De ahí que el poder-gobierno exhibirá claramente, en el pasaje de la década de 1970 a la de 1980, la doble condición de represión y resistencia. Esta última noción es explicitada ahora mediante el concepto de modos de subjetivación y técnicas de sí, como producción o construcción o, mejor aún, como autoconstrucción y gestión personales, como "preocupación" o "inquietud de sí". En otras palabras, cómo la subjetividad puede comportarse y relacionarse consigo misma y con los otros sobre la base de ciertos ideales de sabiduría, estética, economía, dietética, amor, placer, entre otros, como un trabajo sobre la vida que la lleva a transformarse en "obra bella" y en relación con una idea de comunidad y mundo. Entre las prácticas de resistencia que permiten al viviente humano transformarse en sujeto de su propia existencia, Foucault destacará particularmente las relativas a la producción de la verdad y las de libertad.

\section{Epílogo: alcances y potencialidades de las investigaciones analizadas}

Luego de presentar estos desarrollos, resta aún contrastar ambos análisis respecto de la relación de imbricación entre la vida humana y el poder en términos de los alcances y las potencialidades que implican, es decir, de los límites, las virtualidades y las vías de acción y los modos de resistencia que habilitan frente a los análisis y los diagnósticos que proponen.

En el caso de Agamben, es necesario señalar claramente que dicha imbricación excede ampliamente el marco de la modernidad y, hasta se podría decir, de la cultura occidental. De lo que se trata es de poner en evidencia, retomando una tradición que se remonta a Heidegger, la relación inexorable entre el ser puro de la ontología primaria y la nuda vida de la política, o para decirlo en otros términos, entre la metafísica y la política. Así, para el filósofo italiano, toda ontología es una política en la medida en que en la ontología siempre se decide sobre el hombre, es decir, sobre la "humanidad": en ella, el poder siempre decide una modalidad particular en que la vida debe ser definida y, de esta manera, capturada. Agamben afirma que tanto el ser puro como la nuda vida son conceptos vacíos e indeterminados y constituyen, por ello mismo, las claves del destino político de Occidente. De ahí que la investigación "homo sacer" sea también una "saga" particular sobre la ontología, como ya ha sido indicado. Es en este punto donde, en mi opinión, reside un aspecto fundamental de la investigación "homo sacer": el haber puesto en evidencia, en la visión de su autor, los "núcleos mágicos" de la cultura, esa operación 
particular por la cual la vida queda suspendida en el acto de creación de la "máquina antropológica".

Como acabo de señalar, la propuesta de Agamben de leer la relación de imbricación entre la vida y el poder como un desprendimiento de la biopolítica foucaultiana, desvirtúa la formulación originaria del filósofo francés al combinarla con las ideas de Heidegger sobre el ser y al pretender extender el dominio de dicha relación más allá de la modernidad, según una correspondencia tenaz entre lo moderno y lo arcaico. En efecto, Foucault puede llegar a mantener, si este fuera el caso, una relación muy diferente con las ideas heideggerianas y nunca extiende el límite de la biopolítica más allá de la modernidad.

Asimismo, la visión agambeniana sobre la relación vida-poder se puede inscribir ciertamente, además de la ascendencia heideggeriana, en las sendas abiertas por otros pensadores como Aby Warburg (con sus categorías de "ciencia de la cultura" - Kulturwissenschaft- y de "legado" o "supervivencia de la Antigüedad" -Nachleben der Antike-, que presenta sobre todo en su obra El renacimiento del paganismo, 1932), Carlo Ginzburg (en particular, con sus aportes en Los benandanti. Brujería y cultos agrarios entre el siglo XVI y el siglo XVII, 1966) o James Frazer (La rama dorada, 1890).

Agamben expone claramente la tesis que acabo de enunciar, al presentarnos algunos de los resultados de su lectura del modo en que Occidente construye lo "humano" (que denomina "máquina antropológica" de la filosofía occidental o "antropogénesis"), en uno de los trabajos complementarios, pero no por ello menos importante, de la investigación "homo sacer", en el que se explaya abiertamente sobre los fundamentos ontológicos de la imbricación vida-poder. Se trata de Lo abierto. El hombre y el animal, y, en particular, del punto 17 de este libro, que lleva justamente por título "Antropogénesis".

Agamben refiere al curso que Heidegger dicta en Friburgo en 1929-1930, que se propone la definición del concepto de lo "abierto" como uno de los nombres, o más bien, el nombre por excelencia, del ser y del mundo (Heidegger, 1983). En él, Heidegger se pregunta cómo es definido y construido el hombre en la tradición de la ontología occidental, es decir, cuál es justamente la "antropogénesis". Al realizar la genealogía de las concepciones filosóficas en torno de lo humano en la historia de Occidente, el filósofo alemán sostiene que estas pueden ser reducidas a dos formulaciones esenciales que sirven de fundamento a las demás: 1) la tradición filosófica, que refiere al hombre en tanto ser viviente dotado de razón (la tradición que retoma la definición 
aristotélica del zoón politikón); y 2) la tradición bíblica, que lo piensa como una persona, es decir, como un ser creado por la divinidad a su imagen y semejanza.

Ambas tradiciones, sostiene Agamben, coexisten en la modernidad y, mezcladas, dan origen a la forma en que se concibe la noción de sujeto moderno. De ahí, explica el filósofo, el papel de la relación entre metafísica y política en la historia de Occidente y la especial relación entre cultura y poder en el proceso civilizatorio, puesto que, señala, "es en la medida en que el hombre llega esencialmente en la apertura a un cierre, que es posible algo así como una polis y una política" (Agamben, 2002, p. 77). Se trata entonces no solo de dar cuenta de la manera en que se constituyó la matriz socio-política de la modernidad, sino del modo en que el poder y la vida se anudan desde el comienzo del proceso civilizatorio.

De su lectura del curso de Heidegger, Agamben concluye, entre otras ideas, que la ontología, o filosofía primera, no es una disciplina universitaria inofensiva, sino la operación en todo sentido fundamental en la que se realiza la antropogénesis, "el devenir humano de lo viviente" (Agamben, 2002, p. 81). Y agrega:

La metafísica está en juego desde el principio en esta estrategia: concierne precisamente esta metá que completa y toma bajo su cuidado la superación de la physis animal en dirección de la historia humana. Esta superación no es un episodio que se haya realizado de una vez y para siempre, sino un acontecimiento siempre en curso, que decide en cada momento y en cada individuo, lo humano y lo animal, la naturaleza y la historia, la vida y la muerte. (Agamben, 2002, p. 81)

De ahí que Agamben concluya que el conflicto político decisivo, que gobierna cualquier otro conflicto, es, en nuestra cultura, el referido a la animalidad y la humanidad del hombre y que, por lo tanto, "la política occidental es, en otros términos, co-originariamente biopolítica" (Agamben, 2002, p. 82). Esta afirmación debe ser entendida, de todas formas, en los propios términos en que el filósofo entiende la biopolítica, puesto que deforma la noción foucaultiana originaria de este concepto. Siendo consecuente con esta afirmación y, nuevamente de manera provocadora, Agamben sostiene que preguntarse en qué medida el hombre ha sido separado del no hombre y el animal de lo humano es más urgente que tomar posición respecto de las grandes preguntas, los pretendidos valores y los derechos humanos (Agamben, 2002, p. 24). 
Agamben señala que esta urgencia está presente, al menos, desde que la metafísica aristotélica definió el principio de lo viviente. Recuérdese, en este punto, esa definición cuyo recorrido rastrea Arendt en La condición humana a través del derrotero del sintagma zoón politikón de la Política de Aristóteles (y que, en el Estagirita, se completa asimismo con el predicado logón ekhón -capaz de discurso o razón-), retomado en Séneca y luego reintroducido en el pensamiento occidental mediante la traducción modelo de Tomás de Aquino como "homo est naturaliter politicus, id est, socialis" ("el hombre es politico por naturaleza, es decir, social”) (Arendt, 1998, p. 23. Itálica en el original). En nota a pie de página, Arendt explica que "la cita está tomada del Index Rerum, de la edición de Tauro de Santo Tomás (1922). La palabra "politicus" no aparece en el texto, pero el Index resume correctamente el significado de Santo Tomás, como puede comprobarse en la Summa theologica, I. 96.4; II. II.109.3" (Arendt, 1998, p. 23).

Según el planteo de Agamben, la "máquina antropológica" ha articulado durante siglos, en la tradición occidental, el cuerpo y el alma, la vida animal y el logos, lo natural y lo sobrenatural, muy particularmente a través del gobierno. Es en él donde Agamben ubica el verdadero arcano del poder. De ahí que, en su opinión, solo una teoría crítica del gobierno permitirá desactivar esa "máquina gubernamental” y dar lugar a eso que llamamos política.

Por su parte, es necesario subrayar el esfuerzo de Foucault por delinear claramente, en todo momento, el alcance únicamente limitado al tiempo-espacio de la modernidad, de sus análisis sobre la subjetividad, el poder-gobierno y la verdad. En efecto, su esfuerzo de análisis y comprensión es claramente disruptivo en términos de formas históricas al tiempo que no solo ofrece un diagnóstico lúcido de la relación entre la vida y el poder, sino que identifica en ella la potencialidad de la ruptura y el cambio.

Al desarrollar sus análisis sobre el poder-gobierno, las formas que puede asumir la vida y los juegos de veridicción que se producen al interior de dichas relaciones siempre históricas, Foucault nos recuerda, en particular a partir de sus investigaciones de la década de 1970, la posibilidad de la resistencia y la creación con base en nuestros deseos y nuestras necesidades junto con otros. Los modos de subjetivación como ejercicio de poder, y las prácticas de sí muy particularmente en relación con los juegos de verdad, ofrecen un camino para crear otra vida y otro mundo como vida y mundos diferentes a los que se viven. De ahí la potencia que implica la propuesta de análisis de 
Foucault con la idea de un poder-gobierno que no solo es represivo y coactivo, sino también y al mismo tiempo, resistente, libre, imaginativo y productor de vidas y mundos como ejercicio de la resistencia, la crítica y la libertad. Es a estas ideas que responden, específicamente, sus nociones de resistencia, ontología crítica del presente y prácticas de libertad.

Los desarrollos filosóficos a los que estoy aludiendo, tanto en Agamben como en Foucault, demuestran el hecho fundamental del lugar central que la vida ha venido a ocupar en las prácticas que han ido constituyendo la subjetividad moderna y sus inestables formas contemporáneas y el espacio sociopolítico de la modernidad y de aquello que, a falta de un mejor nombre, se puede denominar posmodernidad. Las transformaciones y redefiniciones que la noción de sujeto fue experimentando desde la formación del paradigma moderno, dan cuenta de los distintos modos en que se ha tratado de dar forma a la vida humana, apresándola bajo distintas configuraciones que, sin embargo, permiten constatar -aun desde visiones disímiles como las de Foucault o Agamben, pero también las de Marx, Arendt, Benjamin o Weberun espacio de libre disposición de la vida que hace posible la alienación, la imposibilidad de auto-institución o lo que Agamben llama la nuda vida y Foucault, la biopolítica.

Frente a esta constatación y, sobre todo, frente a la manera en que la vida ha sido configurada en el tiempo-mundo contemporáneo, confinándonos al más ignoto de los contrarios de sus fines enunciados, a una in-existencia que se presenta, sin embargo, como el mejor de los mundos posibles, necesitamos, creo, reivindicar y crear o recrear herramientas de lucha política. En consecuencia, evaluar las implicancias de los ideales modernos de la matriz y la praxis política constituye una tarea urgente e imperiosa, a fin de lograr eventuales rehabilitaciones o nuevas herramientas para poder escuchar claramente el estruendo de la batalla e intervenir en ella.

\section{Referencias}

Agamben, G. (1998). Quel che resta di Auschwitz. L'archivio e il testimone (Homo sacer III). Torino: Bollati Boringhieri. En castellano: (2000). Lo que queda de Auschwitz. El archivo y el testigo. Homo Sacer III. (Trad. A. Gimeno Cuspinera). Valencia: Pre-Textos. 
Agamben, G. (2002). L'aperto. L'uomo e l'animale. Torino: Einaudi. En castellano: (2010). Lo abierto. El hombre y el animal. (Trad. A. Gimeno Cuspinera). Valencia: Pre-Textos.

Agamben, G. (2004). Stato di eccezione. Homo sacer II, I. Torino: Bollati Boringhieri. En castellano: (2004). Estado de excepción. Homo sacer, II, 1. (Trad. F. Costa e I. Costa). Buenos Aires: Adriana Hidalgo.

Agamben, G. (2005). Homo sacer. Il potere sovrano e la nuda vita. Torino: Einaudi. En castellano: (1998). Homo Sacer I. El poder soberano y la nuda vida. (Trad. A. Gimeno Cuspinera). Pre-textos: Valencia.

Agamben, G. (2007). Il Regno e la Gloria. Per una genealogia teologica dell'economia e del governo. Homo sacer II, 2. Torino: Neri Pozza Editore. En castellano: (2008). El Reino y la Gloria. Para una genealogía teológica de la economía y del gobierno. Homo sacer, II, 2. (Trad. F. Costa, E. Castro y M. Ruvituso). Buenos Aires: Adriana Hidalgo.

Arendt, H. (1988). The Human Condition. Chicago \& London: The University of Chicago Press. En castellano: (1993). La condición humana. (Trad. R. Gil Novales). Barcelona: Paidós.

Arendt, H. (1992). Eichmann in Jerusalem. A Report on the Banality of Evil. London/New York: Penguin Books. En castellano: (1999). Eichmann en Jerusalén: un estudio sobre la banalidad del mal. (Trad. C. Ribalta). Barcelona: Lumen.

Benjamin, W. (1980). Über den Bregriff der Geschichte. Gesammelte Schriften, Band I/2. Frankfurt am Main: Suhrkamp. En castellano: (2008). Sobre el concepto de historia. Obras I, 2. (Trad. A. Brotons Muñoz). Madrid: Abada.

Éribon, D. (1989). Michel Foucault (1926-1984). Paris: Flammarion. En castellano: (2006). Michel Foucault. (Trad. Th. Kauf). Barcelona: Anagrama.

Foucault, M. (1994). « Omnes et singulatim » : vers une critique de la raison politique. Dits et écrits IV 1980-1988 (pp. 134-161). Paris: Gallimard. En inglés: "Omnes et singulatim": Towards a Criticism of Political Reason (Trad. P. E. Dauzat). McMurrin, S. (Ed.) (1981). The Tanner Lectures on Human Values. t. II. Salt Lake City: University of Utah 
Press. En castellano: (2008). "Omnes et singulatim: hacia una crítica de la "razón política"”. En Foucault, M. Tecnologías del yo y otros textos afines. (Trad. M. Allendesalazar). Buenos Aires: Paidós.

Foucault, M. (1995). Histoire de la sexualité 1. La volonté de savoir. París: Gallimard. En castellano: (2002). La voluntad de saber, tomo I de Historia de la sexualidad (Trad. U. Guiñazú). Buenos Aires: Siglo XXI.

Foucault, M. (1997). Il faut défendre la société. Cours au Collège de France. 1976. París: Hautes Études-Gallimard/Seuil. En castellano: (2000). Defender la sociedad. Curso en el Collège de France (1975-1976) (Trad. H. Pons). FCE: Buenos Aires.

Foucault, M. (2004). Sécurité, territoire, population. Cours au Collège de France. 1977-1978. París : Hautes Études-Gallimard/Seuil. En castellano: (2006). Seguridad, territorio y población. Curso en el Collège de France (1977-1978) (Trad. H. Pons). FCE: Buenos Aires.

Heidegger, M. (1983). Gesamtausgabe, XXIX-XXX: Die Grundbegriffe der Metaphysik. Welt - Endlichkeit - Einsamkeit. Frankfurt am Main: Klostermann. En castellano: (2007). Los conceptos fundamentales de la metafisica: Mundo, Finitud, Soledad (Trad. J. Ciria Cosculluela). Madrid: Alianza Editorial.

Schmitt, C. (2005). Teología política. Cuatro ensayos sobre la soberanía (Trad. F. J. Conde). Buenos Aires: Editorial Struhart \& Cía. 